\title{
Quantitative Analysis of High Temperature Alloys with an Ion Microanalyzer
}

\author{
YOSHIAKI OKAZIMA* AND YUKIYOSHI AIZAWA*
}

(Received 31 March 1977)

\begin{abstract}
Quantitative analysis of constituent elements of high temperature alloys was investigated with an ion microanalyzer. Contents of constituent elements are different from one alloy to the other in high temperature alloys such as Inconel and Hastelloy and there is not a common main constituent like iron in low alloy steels. For calibrating methods, total ions and nickel ions were selected as a reference. The peak intensity ratio of each element to nickel is used, as it is assured that this is proportional to the concentration ratio in alloys.
\end{abstract}

\section{Introduction}

The constituents and the impurities contained in high temperature alloys are usually determined by the chemical analyses such as gravimetric, volumetric and colorimetric method" ${ }^{12}$. Atomic absorption spectrophotometry, radioactivation analysis and X-ray fluorescence analysis are another means for the determination. ${ }^{2}$ By these methods, the average concentrations of constituents and impurities of the alloys are obtained. But, sometimes it is necessary to make clear the concentration profiles of constituents in a thin layer at a surface as well as the mean concentrations in a bulk.

An ion microanalyzer (IMA) enables us to carry out analyses of the elements contained in a very thin layer or in a small selected volume. Therefore, the ion microprobe mass analysis is expected to provide the concentration profiles of the elements in a surface layer of the high temperature alloys. But, the confirmed quantitative methods with an ion microanalyzer has not been established yet.
The quantitative determination of small amounts of elements in low alloy steels with an ion microanalyzer was investigated by a thermodynamic approaching method and by a calibration method. The thermodynamic approaching method was investigated by Andersen and Hinthorne ${ }^{3)}$ and was applied to analyze the small amount of elements in low alloy steels by Tamura et al." But, the obtained value by this method has large error. Therefore, this method could not be applied for the accurate determination of the main elements of the high temperature alloys. The calibration method was investigated by Sato et al. ${ }^{5.6)}$ This method gives more accurate values than the thermodynamic approaching method on the analyses of small amounts of elements in low alloy steels. In the low alloy steels, iron is the principal constituent and could be used as a reference element. In the case of high temperature alloys, contents of constituent elements are different from one alloy to the other and there is not the principal constituent like iron in the low alloy steels.

* Hitachi Research Lab., Hitachi Ltd., 4026, Kuji-machi, Hitachi-shi, Ibaraki 319-12 


\section{Y. Okazima and Y. Aizawa}

The present paper describes on the reference which is available to determine quantitatively the constituents of high temperature alloys by the calibration method.

\section{Experimental}

\subsection{Materials}

Specimens of high temperature alloys used were the standard samples prescribed by the
Committee on Analytical Chemistry of Nuclear Fuels and Reactor Materials, Japan Atomic Energy Research Institute. Table 1 gives the concentration of main constituents obtained by chemical analysis. These specimens were cut into $5 \mathrm{~mm}$ thick and $5 \times 5 \mathrm{~mm}$ in size and polished with diamond paste and ultrasonically cleaned in alcohol and ether.

Table 1. Contents of main constituents in high temperature alloys.

\begin{tabular}{ccccccccc} 
Specimen & \multicolumn{7}{c}{ Concentration (\%) } \\
& $\mathrm{Mn}$ & $\mathrm{Ni}$ & $\mathrm{Cr}$ & $\mathrm{Fe}$ & $\mathrm{Co}$ & $\mathrm{Ti}$ & $\mathrm{Al}$ & $\mathrm{Nb}$ \\
$\mathrm{R}-2$ & 0.08 & 73.9 & 15.5 & 6.3 & 0.03 & 2.75 & 0.81 & 0.77 \\
$\mathrm{R}-5$ & 0.31 & 74.2 & 16.0 & 8.4 & 0.14 & 0.18 & 0.10 & - \\
$\mathrm{R}-6$ & 0.63 & 68.6 & 17.7 & 11.3 & 0.01 & 0.49 & 0.42 & - \\
R-7 & 1.37 & 32.4 & 21.0 & 43.6 & 0.29 & 0.28 & 0.30 & - \\
R-8 & 1.02 & 31.6 & 20.8 & 44.4 & 0.40 & 0.40 & 0.53 & -
\end{tabular}

\subsection{Experimental procedure}

An ion microanalyzer of Hitachi type IMA-2 was used for this study. Argon ionized by a duoplasmatron was accelerated from 8 to $13 \mathrm{kV}$ and struck the sample. The beam was focused to about $0.8 \mathrm{~mm}$ diameter. The current density of primary ions at the sample was 0.1 to 0.8 $\mathrm{mA} / \mathrm{cm}^{2}$. The pressure in the sample chamber was $2 \times 10^{-7}$ Torr. Secondary ions sputtering from the sample surface were accelerated at a voltage of $3 \mathrm{kV}$ and analyzed with a mass spectrometer.

\subsection{Principle of quantitative analysis}

The secondary ion current $I_{x}$ of an specific isotope of element $\mathrm{X}$ is given $\mathrm{by}^{6}{ }^{6}$

$$
I_{\mathrm{x}}=\eta_{\mathrm{x}} S_{\mathrm{x}}^{+} C_{\mathrm{x}} I_{\mathrm{p}}
$$

where $\eta_{x}$ is the transmission of the instrument between sample and collector, $S_{\mathrm{x}}^{+}$the ion yield of element $\mathrm{X}, C_{\mathrm{x}}$ the concentration of element $\mathrm{X}$ and $I_{\mathrm{p}}$ the current density of primary ions.
Thus the ratio of the secondary ion current of an element $\mathrm{X}$ to a reference element (matrix) $\mathrm{R}$ is given by

$$
\frac{I_{\mathrm{x}}}{I_{\mathrm{R}}}=S(\mathrm{rel})^{+} \frac{C_{\mathrm{x}}}{C_{\mathrm{R}}}
$$

where $I_{R}$ is the secondary ion current of reference element $R, C_{R}$ the concentration of a reference element $\mathrm{R}$ and $S(\mathrm{rel})^{+}$the ratio of the ion yield of element $\mathrm{X}$ to a reference element $\mathrm{R}$. If the Eq. 2 is consistent with determination of constituents of high temperature alloys, a calibration curve would be obtained by plotting $I_{\mathrm{x}} / I_{\mathrm{R}}$ as a function of $C_{\mathrm{x}} / C_{\mathrm{R}}$.

\section{Results}

\subsection{Working conditions}

In order to obtain unchanged intensity of the secondary ions sputtering from the samples, the effects of accelerating voltage for the primary ions, $E_{\mathrm{p}}$, and current density of primary ions, 


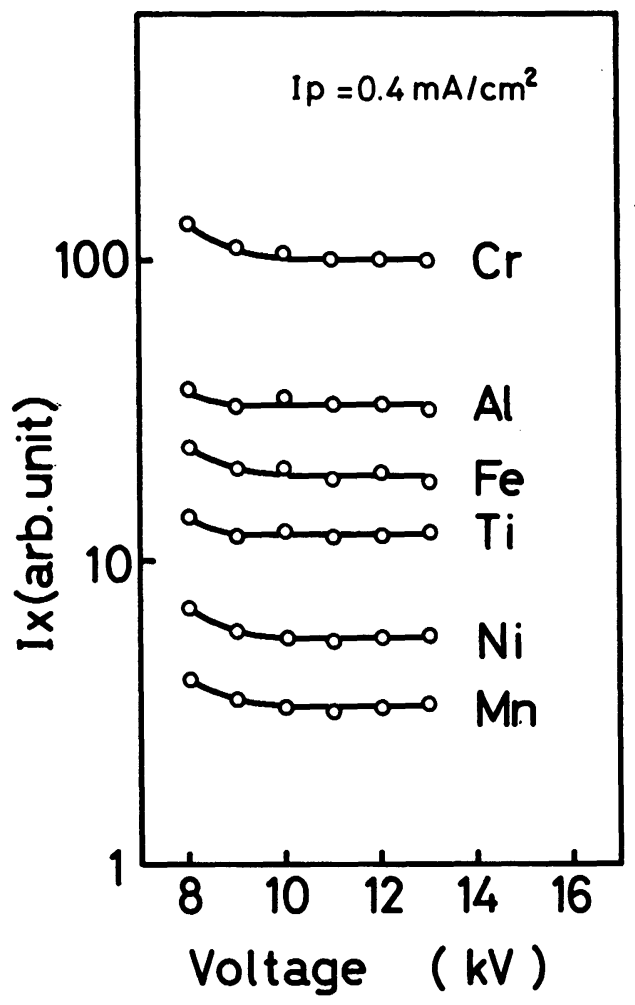

Fig. 1. Relation between accelerating voltage for primary ions and intensity of secondary ions.

$I_{\mathrm{p}}$, were investigated in the range of 8 to $13 \mathrm{kV}$ and 0.1 to $0.8 \mathrm{~mA} / \mathrm{cm}^{2}$, respectively.

Figure 1 shows relations between the accelerating voltage for the primary ions and the intensity of secondary ions. The intensity of each secondary ion decreases with the accelerating voltage and becomes constant at voltage above $10 \mathrm{kV}$.

Figure 2 shows relations between the current density of primary ions and the intensity of sedondary ions. According to the Eq. 1, the intensity of secondary ions, $I_{\mathbf{x}}$, is proportional to the current density of promary ions, $I_{\mathrm{p}}$. In Fig. 2, proportional relations are observed in each elements in the range of 0.2 to $0.5 \mathrm{~mA} / \mathrm{cm}^{2}$.

Sample surfaces are usually contaminated wit $\mathrm{h}$ impurities such as polishing agents, oxygen,

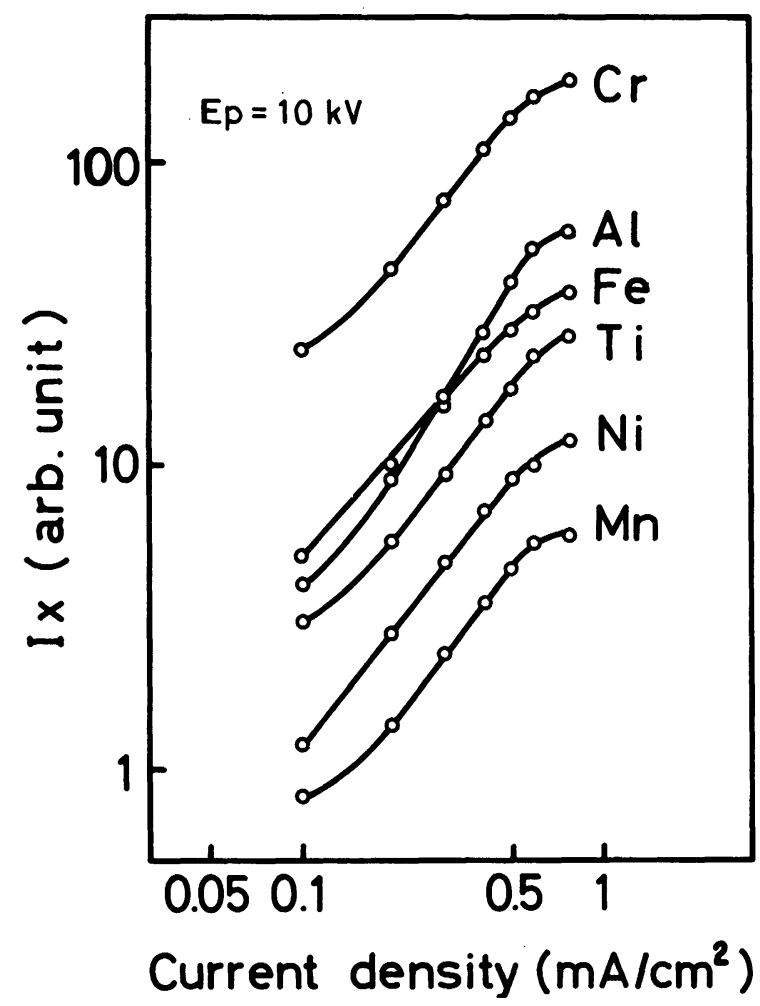

Fig. 2. Relation between current density of primary ions and intensity of secondary ions.

water and hydrocarbons and this makes quantitative analysis to be difficult. Sputtering is effective to remove the impurities on surface. Figure 3 shows relations between the bombardment time and the intensity of secondary ions. In the early stages of bombardment, the intensity varies rapidly. However, stable signals could be obtained after bombardment for ca. $15 \mathrm{~min}$.

From these results, working conditions in Table 2 were determined to obtain the unchanged intensity of secondary ions.

\subsection{Calibration curves}

As described above, contents of constituent elements in high temperature alloys are different from one alloy to another and there is not a common main constituent like iron in low alloy steels. So, at first total ions was selected as a 


\section{Y. Okazima and Y. Aizawa}

Table 2. Working conditions for quantitative analysis .

Ionic species
Accelerating voltage for primary ions
Current density of primary ions
Beam diameter
Pressure in sample chamber
Preliminary sputtering time

Accelerating voltage for secondary ions
Argon $\left(\mathrm{Ar}^{+}\right)$

$10 \mathrm{kV}$

$0.4 \mathrm{~mA} / \mathrm{cm}^{2}$

$0.8 \mathrm{~mm}$

$2 \times 10^{-7}$ Torr

$15 \min$

$3 \mathrm{kV}$

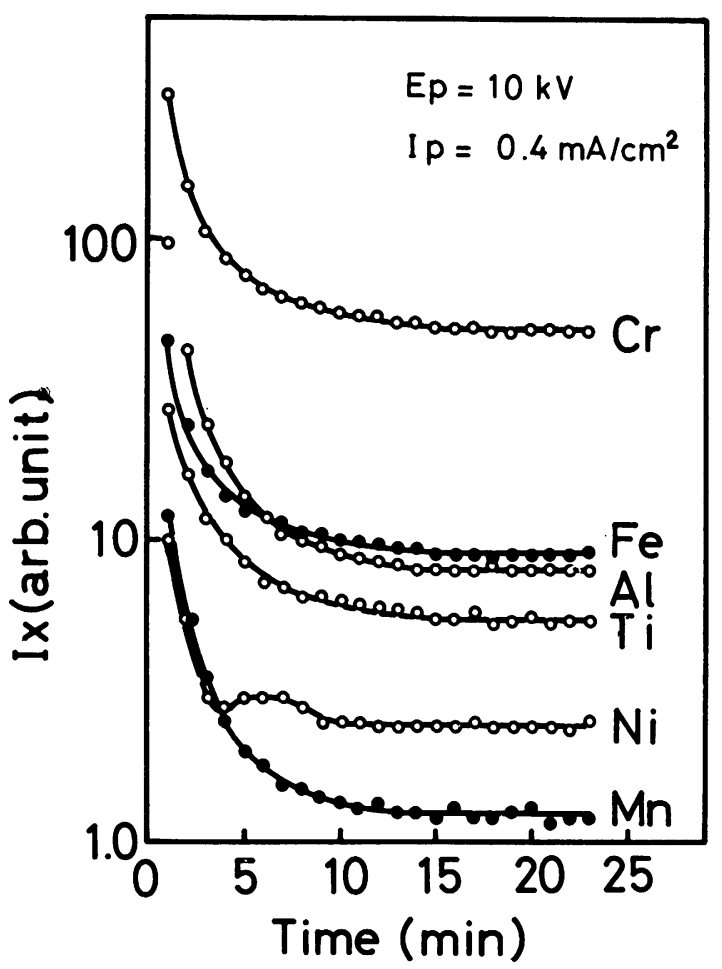

Fig. 3. Relation between bombardment time and intensity of secondary ions.

reference element in Eq. 2.

Total ions are detected as ion currents at a slit between an electric field and a magnetic field of the mass spectrometer and are proportional to the sum of secondary ions of each element. Under the conditions of Table 2, intensity ratios of a specific secondary ion and total ions were plotted as a function of the concentration of each element. But, linear relations were not obtained. The ion yield of each element differs too greatly in the case of the ionization by argon ions.". The difference makes the total ions of one alloy different from that of another. Furthermore, as shown in Fig. 4, the ion yield of each element differs from one alloy to the other. It is considered that these differences make total ions to be difficult to use as a reference. 


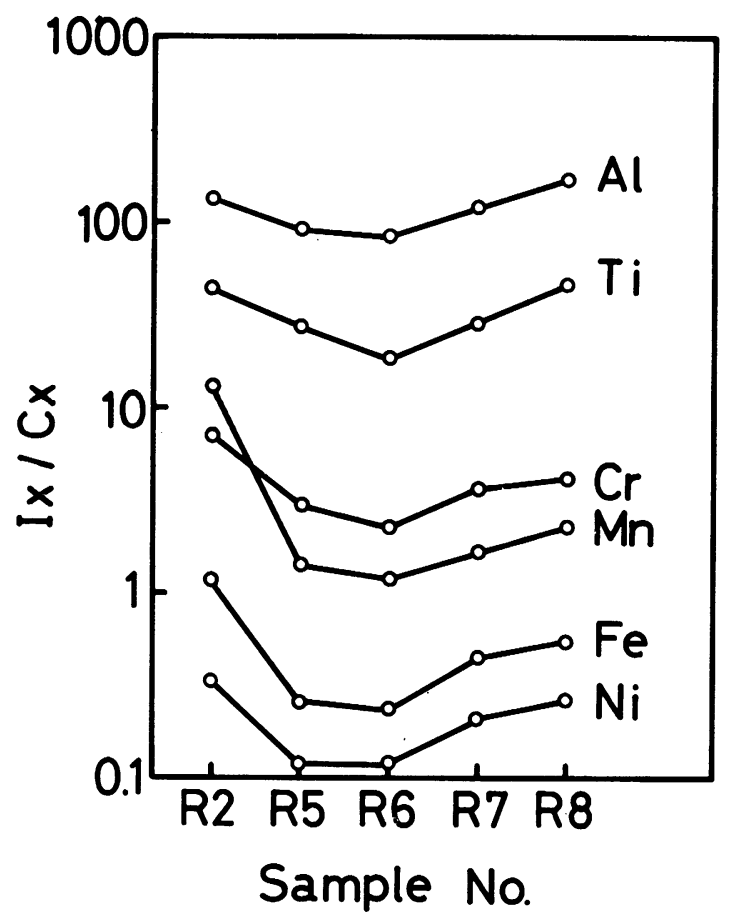

Fig. 4. Ion yields of each element with samples.

Nickel is contained in large quantities in many high temperature alloys. Figure 5 shows the relative ion yields of each element to nickel with test samples. The relative ion yields of each element to nickel are almost constant, except that of sample R-2. Therefore, nickel might be selected as a reference element. Intensity ratios of the secondary ions of each element to nickel, $I_{\mathrm{x}} / I_{\mathrm{Ni}}$, were plotted as a function of the concentration ratios of each element to nickel, $C_{\mathrm{x}} / C_{\mathrm{Ni}}$. As shown in Fig. 6, linear relations are obtained between $I_{\mathrm{x}} / I_{\mathrm{Ni}}$ and $C_{\mathrm{x}} / C_{\mathrm{Ni}}$.

But, there are some remote points from the calibration curves of each element. These are points of sample R-2. That is, the relative ion yields of each element to nickel in sample R-2 are different from those of other samples. The sample R-2 differs from other samples in that it contains niobium. In the low alloy steels, a similar phenomenon was observed ${ }^{6.8)}$. The intensity ratios of each element to iron of niobium containing alloy differ from those of other low alloy steels such as $\mathrm{Fe}-\mathrm{Mn}$ alloys and $\mathrm{Fe}-\mathrm{Ni}$ alloys. It is considered to be the reason for difference that niobium produces carbide with carbon in the alloy.

The calibration curve of cobalt has a smaller slope than those of other elements. A reason for this is considered as follows. The peak of $m / e=59$ used for cobalt contains also contribution from ${ }^{58} \mathrm{NiH}^{+}$ions. The contents of nickel are much higher than that of cobalt in the high temperature alloys. Therefore, the slope of calibration curve of cobalt would be different from other elements according to the large background of ${ }^{58} \mathrm{NiH}^{+}$ions.

In this method, it is necessary that nickel is analyzed by other methods such as chemical analysis and X-ray fluorescence spectrometry. 
Y. Okazima and Y. Aizawa

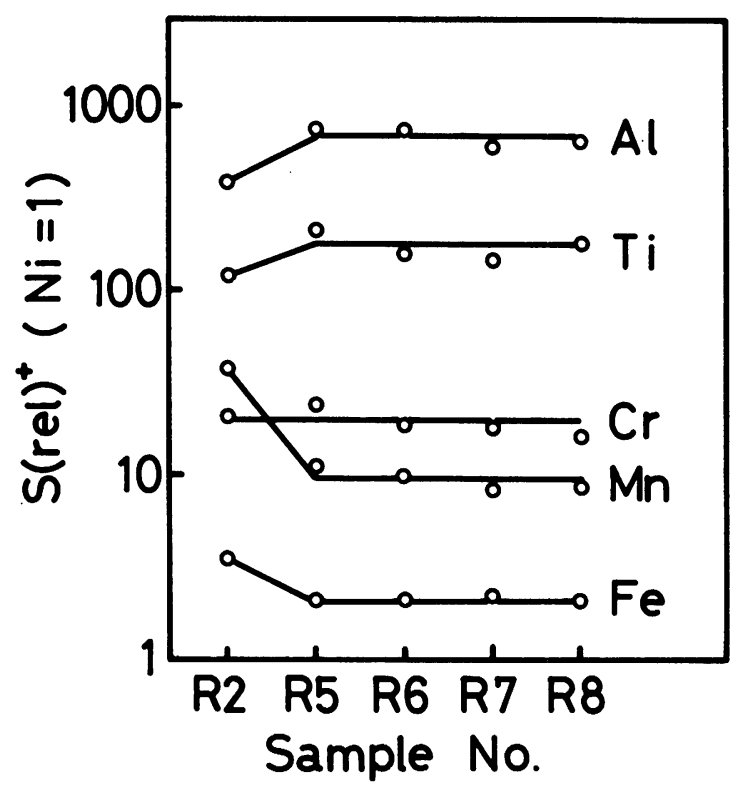

Fig. 5. Relative ion yields of each element to nickel with samples.

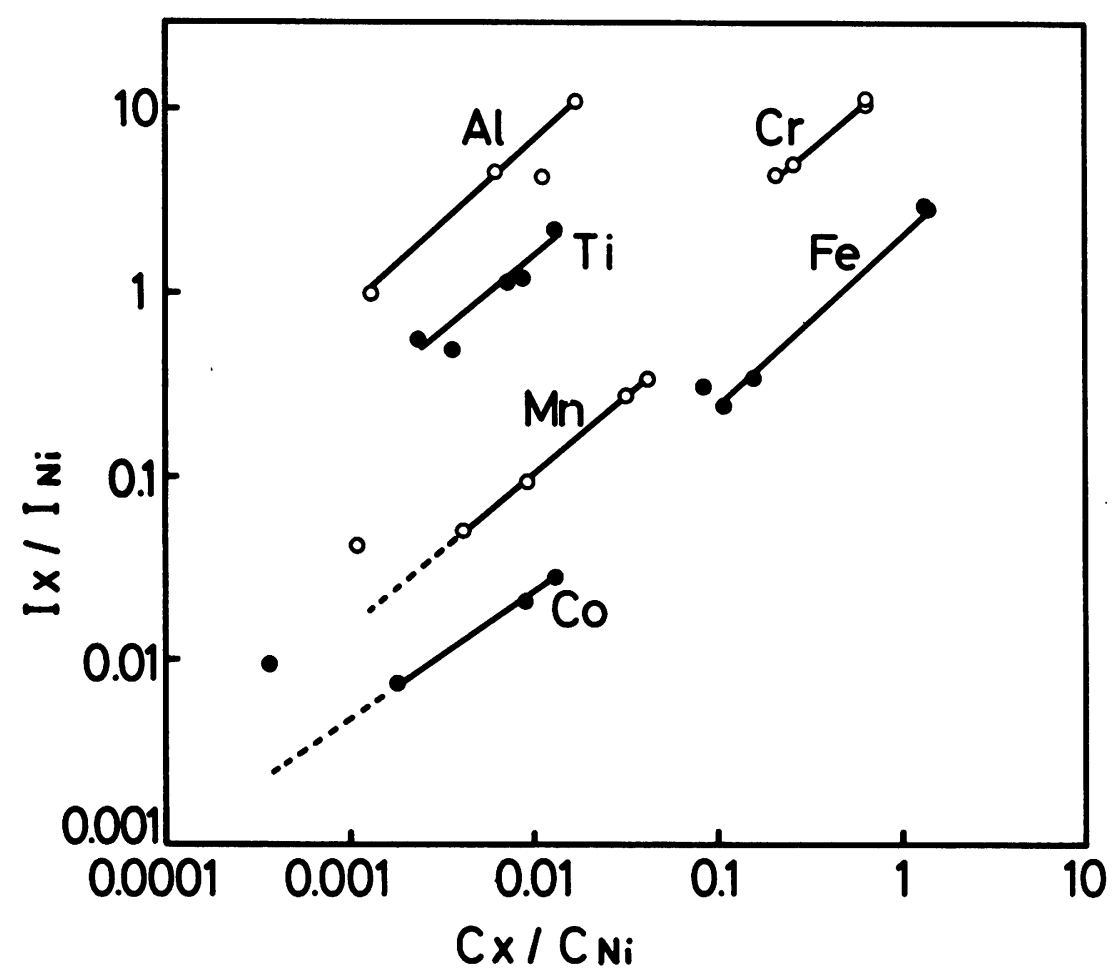

Fig. 6. Calibration curves. 


\section{Quantitative Analysis of High Temperature Alloys with an Ion Microanalyzer}

\subsection{Comparison of IMA method with chemical analysis}

The established method was applied to analyses of heat exchanger materials of a nuclear reactor. Table 3 gives the results obtained by IMA method, where nickel was analyzed by chemical analysis. The values with IMA are nearly equal to those of chemical analysis.

Table 3. Comparison of IMA method with chemical analysis .

\begin{tabular}{|c|c|c|c|c|c|c|c|}
\hline \multirow[t]{2}{*}{ Specimen } & \multirow[t]{2}{*}{ Method } & \multicolumn{4}{|c|}{ Concentration (\%) } & \multirow[b]{2}{*}{$\mathrm{Fe}$} & \multirow[b]{2}{*}{ Co } \\
\hline & & $\mathrm{Al}$ & $\mathrm{Ti}$ & $\mathrm{Cr}$ & $\mathrm{Mn}$ & & \\
\hline \multirow[t]{2}{*}{ A } & IMA & 0.55 & 1.9 & 13.0 & 0.16 & 7.7 & 0.56 \\
\hline & $\mathrm{CA}^{*}$ & 0.56 & 1.98 & 13.5 & 0.15 & 7.8 & 0.58 \\
\hline \multirow[t]{2}{*}{ B } & IMA & 0.58 & 2.6 & 16.1 & 0.07 & 6.3 & 0.1 \\
\hline & $\mathrm{CA}$ & 0.60 & 2.65 & 15.3 & 0.11 & 6.8 & 0.04 \\
\hline \multirow[t]{2}{*}{$\mathrm{C}$} & IMA & 0.06 & 0.25 & 20.0 & 0.22 & 4.3 & 0.22 \\
\hline & $\mathrm{CA}$ & 0.10 & 0.23 & 21.7 & 0.21 & 4.3 & 0.17 \\
\hline \multirow[t]{3}{*}{ D } & IMA & 0.07 & tr. & 23.0 & 0.55 & 18.1 & 1.2 \\
\hline & $\mathrm{CA}$ & 0.11 & tr. & 21.4 & 0.56 & 17.9 & 1.05 \\
\hline & & \multicolumn{6}{|c|}{ * Chemical analysis } \\
\hline
\end{tabular}

\section{References}

1) S. Tsujimura, J. At. Energy Soc. Japan, 17, 8 (1975).

2) J. L. Hague, E. E. Maczkowski and H. A. Bright, J. Res. National Burear Standard, 53, 353 (1954).

3) C. A. Andersen and J. R. Hinthorne, Anal. Chem., 45, 1421 (1973).
4) T. Kondo, H. Tamura, T. Ishitani and K. Nakamura, Mass Spect., 23, 221 (1975).

5) R. Matsumoto, K. Sato and K. Suzuki, Tetsu to Hagane, 60, 254 (1974)

6) K. Sato and K. Tsunoyama, Oyo Butsuri, 45, 828 (1976).

7) H. E. Beske, Z. Naturforsch., 22a, 459 (1967).

8) J. Okano, Mass Spect., 24, I (1976). 